\title{
Drug-induced toxic Myocarditis: Doxorubicin once again leading to Heart Failure
}

\author{
Teixeira-Tavares $\mathrm{N}^{1}$, Cunha $\mathrm{F}^{2}$ \\ ${ }^{1}$ Serviço de Oncologia Médica, Centro Hospitalar de São João \\ ${ }^{2}$ Serviço de Medicina Interna, Centro Hospitalar de São João
}

\begin{abstract}
Treatment protocols in Oncology experienced massive changes in recent decades which have contributed to improve the morbidity and mortality of cancer. However, these advances were often achieved at the expense of significant side effects. The authors describe a case of a 62 year old woman with Follicular non-Hodgkin's Lymphoma who develops a toxic Myocarditis due to Doxorubicin. Anthracyclines cardiotoxicity is an established irreversible complication. There are a few measures that shall be taken into account in order to supervise, prevent and treat these patients.

Keywords: Doxorubicin; Cardiotoxicity; Myocarditis; Heart Failure; Cancer

Palabras clave: Doxorubicina; Cardiotoxicidad; Miocarditis; Insuficiencia Cardíaca; Cáncer
\end{abstract}

\section{Introduction}

The cardiotoxicity of chemotherapeutic agents is a problem that has attracted the attention of clinicians in order to improve monitoring of clinical condition, prevention and treatment of complications. Anthracyclines (eg. doxorubicin) are the most widely pharmacological class related to cardiotoxicity. They are used in lymphomas, leukemias, sarcomas and breast cancer ${ }^{1}$. Their cardiotoxicity is irreversible, cumulative, dose-dependent and it's due to direct lesion/loss of myocites. Heart Failure (HF) can present acutely with high doses but it is most frequently a late-onset complication?

\section{Case Presentation}

A 62 year old caucasian woman has a medical history of Arterial Hypertension, type 2 Diabetes Mellitus treated with oral hypoglicemic agents and Pulmonary Emphysema. She is diagnosed with grade 3 Follicular non-Hodgkin's Lymphoma and starts a chemotherapy regimen with R-CHOP (Rituximab, Cyclophosphamide, Doxorubicin, Vincristine and Prednisone) with a 3-week periodicity. Prior to treatment initiation there was assured adequate control of cardiovascular risk factors, normal sinus rhythm in Electrocardiogram (ECG), negative cardiac biomarkers (troponin I and b-natriuretic peptide [BNP]) and a two-dimensional transthoracic echocardiogram (TTE) without significant abnormalities (left ventricular ejection fraction [LVEF] of $68 \%$, determined by Simpson method). Two days after the seventh cycle of chemotherapy, the patient was admitted in the Emergency Department (ED) with severe shortness of breath, orthopnea, retrosternal chest pain exacerbated by inspiration and symmetric leg swelling. There were no other symptoms, such as paroxysmal nocturnal dyspnoea or fever.

The physical examination showed tachypneia with use of accessory respiratory muscles, tachycardia, jugular venous distention at $90^{\circ}(4$ $\mathrm{cm}$ ), decreased breath sounds in the lower third of both lungs and exuberant peripheral edemas. The remainder of the physical examination was otherwise normal.

ECG showed sinus tachycardia, normal PR interval with no depression and no ST segment abnormalities. Arterial blood gases documented a hypoxemic respiratory failure. Laboratory tests (Table 1) revealed marked increase of BNP (2291.7 pg/mL) and Troponin
Table 1. Laboratory tests results.

\begin{tabular}{|l|c|c|c|c|}
\hline $\begin{array}{l}\text { Laboratory } \\
\text { parameters }\end{array}$ & ED & $\begin{array}{c}\text { 3-Month } \\
\text { Follow-up }\end{array}$ & $\begin{array}{c}\text { Normal } \\
\text { range }\end{array}$ & Units \\
\hline Haemoglobin & 9.8 & 13.1 & $12.0-16.0$ & $\mathrm{~g} / \mathrm{dL}$ \\
\hline Leucocytes & 12.24 & 5.96 & $4.0-11.0$ & $\times 10 \wedge 9 / \mathrm{L}$ \\
\hline Neutrophils & 94.4 & 46 & $53.8-69.8$ & $\%$ \\
\hline Platelets & 192 & 100 & $150-400$ & $\times 10 \wedge 9 / \mathrm{L}$ \\
\hline Glucose & 102 & 189 & $75-115$ & $\mathrm{mg} / \mathrm{dL}$ \\
\hline Urea & 61 & 117 & $10-50$ & $\mathrm{mg} / \mathrm{dL}$ \\
\hline Creatinine & 1.3 & 1.17 & $0.6-1.0$ & $\mathrm{mg} / \mathrm{dL}$ \\
\hline Sodium & 132 & 139 & $135-147$ & $\mathrm{mEq} / \mathrm{L}$ \\
\hline Potassium & 5.5 & 5.1 & $3.5-5.1$ & $\mathrm{mEq} / \mathrm{L}$ \\
\hline C-Reactive Protein & 4.1 & - & $<3.0$ & $\mathrm{mg} / \mathrm{L}$ \\
\hline BNP & 2291.7 & 1025 & $<100$ & $\mathrm{pg} / \mathrm{mL}$ \\
\hline Troponin I & 0.554 & 0.174 & $<0.08$ & $\mathrm{ng} / \mathrm{mL}$ \\
\hline CK-MB & 8 & 2.8 & $<6.4$ & $\mathrm{ng} / \mathrm{mL}$ \\
\hline Myoglobin & 349 & 96.6 & $<146.9$ & $\mathrm{ng} / \mathrm{mL}$ \\
\hline
\end{tabular}

I $(0.554 \mathrm{ng} / \mathrm{mL})$. Furthermore, there was documented a serum creatinine escalation, representing a type I Cardiorrenal Syndrome. The chest $x$-ray (Figure 1) revealed cardiomegaly, Kerley B lines and right pleural effusion.

The TTE showed severe left ventricular systolic dysfunction with an ejection fraction of 25\% (Simpson method), grade III diastolic dysfunction and anterior wall hypokinesis.

A diagnosis of Acute Heart Failure secondary to Anthracycline cardiotoxicity was established.

The patient immediately started therapy with furosemide, beta blocker (nebivolol $5 \mathrm{mg} \mathrm{id}$ ) and angiotensin converting enzyme (ACE) inhibitor (lisinopril $5 \mathrm{mg}$ id). It was difficult to taper the dose of the prognosis modifying therapy due to arterial hypotension. The patient 
remained without chest pain or de novo ECG abnormalities. With excellent urinary output leading to the correction of hypervolemia and respiratory failure, serum creatinine and urea faced a small decline, as well as hyponatremia and hyperkalemia became corrected. We believe the increase in Troponin I must be correlated with the physiopathological mechanism of cardiomyocyte injury by anthracyclines - direct lesion of the cell with loss of myocites - generating a toxic Myocarditis. It was decided not to perform a cardiac catheterization due to the absence of angina or clinical suspicion of coronary disease, and due to the potential nefrotoxicity of contrast agents.

Despite a satisfactory clinical response in the acute setting, the patient remained with exertion dyspnea and was discharged two weeks later with a Class III New York Heart Association functional status. Chemotherapy was suspended and patient remained with haematological surveillance. Three months after discharge, revaluation with a TTE showed deterioration of LVEF to $15 \%$. Serum Troponin I levels were slightly above the upper limit of normal but sill decreasing and it was established a value of $1025 \mathrm{pg} / \mathrm{mL}$ as the "dryBNP" (Figure 2).

\section{Discussion}

Anthracyclines may lead to an irreversible (type I) cardiotoxicity. Other drugs (eg. trastuzumab) may encompass a reversible (type II) cardiotoxicity 1,3,5.

This case report represents an early-onset chronic progressive HF secundary to a Toxic Myocarditis, which can occur in around $2 \%$ of patients during therapy or within the first year of treatment. Cardiotoxicity is related to a cumulative effect (Table 2). The maximum lifetime cumulative dose for doxorubicin is limited to $400-550 \mathrm{mg} / \mathrm{m}^{2}{ }^{1}$.
Figure 1. Upper panel: X-ray showing cardiomegaly, Kerley B lines and right pleural effusion. Lower panel: $X$-ray at 3-month follow-up.

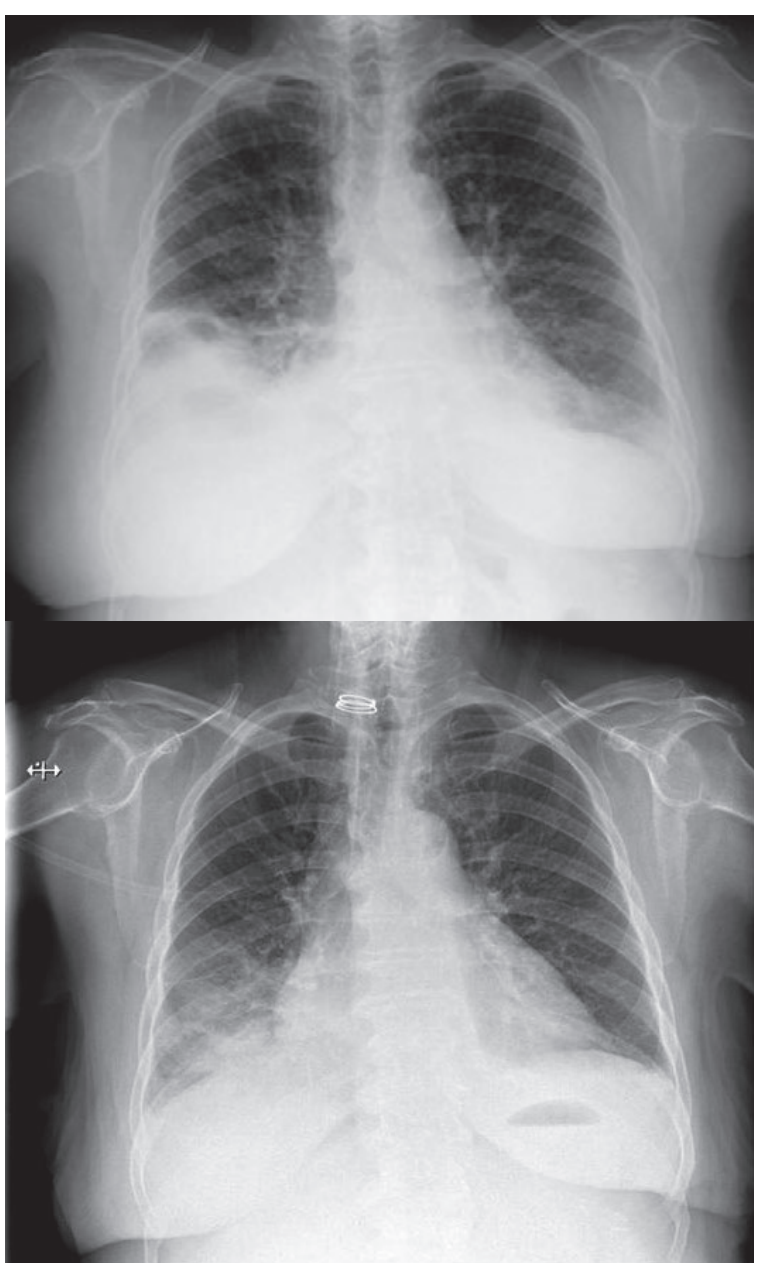

Figure 2. Cardiac biomarkers evolution. Prior to treatment initiation, both Troponin I and BNP were negative. Two days after the seventh cycle of R-CHOP, the patient was admitted in the ED (vertical dashed line) and both BNP and Troponin were rising. The three-month follow up showed a slow progressive decline in Troponin I. *BNP 1025 pg/mL documented as "dry-BNP".

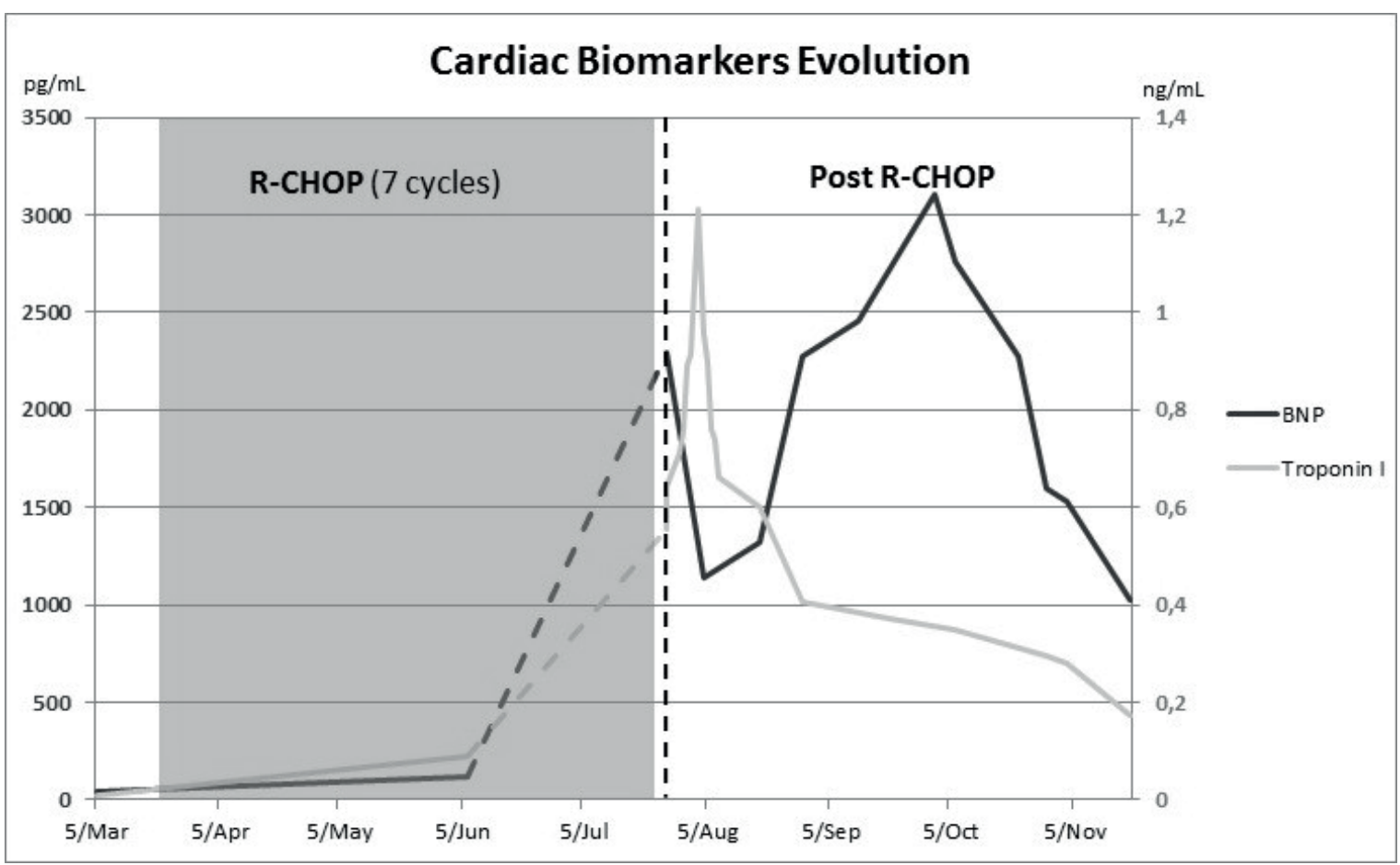


Table 2. Doxorubicin cumulative toxicity ${ }^{1}$

\begin{tabular}{|c|c|}
\hline Cumulative dose & Probability of developing HF \\
\hline $400 \mathrm{mg} / \mathrm{m} 2$ & $3-5 \%$ \\
\hline $550 \mathrm{mg} / \mathrm{m} 2$ & $7-26 \%$ \\
\hline $700 \mathrm{mg} / \mathrm{m} 2$ & $18-48 \%$ \\
\hline
\end{tabular}

Our patient fulfilled 7 cycles of R-CHOP, with a $90 \mathrm{mg}$ doxorubicin dose per cycle, which represents a cumulative dose of $630 \mathrm{mg}$ (below the maximum cumulative dose estimated to the patient $-720 \mathrm{mg}$ ). Female gender, concomitant use of cyclophosphamide and age are important risk factors that may have contributed to the harmful effect of anthracyclines in this case. Other conditions may increase cardiotoxicity, such as doxorubicin intravenous bolus administration (instead of perfusion), history of chest irradiation, underlying cardiovascular disease and increase in cardiac biomarkers during and after previous administrations ${ }^{1,3}$.

Before treatment initiation, cardiovascular risk assessment is required. Cardiovascular risk factors should be aggressively treated ${ }^{2}$ and if cardiotoxicity remains a great concern, an alternative chemotherapeutic regimen with less known cardiotoxicity should be found. Patients must be monitored during and after chemotherapy - late-onset left ventricular dysfunction should always be suspected along their lives ${ }^{1,5}$.

Doppler TTE remains the election tool for baseline cardiologic screening and follow up of cancer patients during or after the completion of cardiotoxic regimens. ${ }^{6}$

Some measures may decrease the risk of anthracyclines cardiotoxicity: using the lowest necessary dose as a continuous infusion to reduce peak plasma levels of the drug, avoiding concomitant use of other cardiotoxic drugs and whenever there is evidence of equal efficacy or superiority of non-anthracycline regimens, they should be considered ${ }^{1}$. Lipossomal anthracyclines are associated with a lower incidence of left ventricular dysfunction ${ }^{3}$.

A wide variety of drugs are being studied for cardiotoxici$t^{3}$. Dexrazoxan is an intracellular iron chelating agent that acts preventing the anthracycline oxidative stress inductive process. Up to date, this is the only drug approved by FDA for cardiotoxicity prevention ${ }^{5}$. Quercetin is another oxidative stress reducing agent that acts by modulating Bmi-1 expression, therefore decreasing in vitro doxorubicin-induced cardiotoxicity. Studies in humans are lacking ${ }^{7}$. Metformin, an oral antidiabetic agent, has proven in vitro benefitt, ${ }^{9}$. Studies in humans are lacking.

Beta-Blockers and ACE inhibitors are drugs extensively studied in HF and they should be used to treat these patients once HF develops. Doses should be increased to maximally tolerated ones. Diuretics (eg. furosemide) should be used to control symptoms of congestion? ${ }^{2}$.

Assuming the irreversibility of the cardiotoxicity, patient's prognosis is poor.

\section{References}

1. Curigliano G, Cardinale D, Suter T, Plataniotis G, de Azambuja E, Sandri MT, et al. European Society of Medical Oncology. Cardiovascular toxicity induced by chemotherapy, targeted agents and radiotherapy: ESMO Clinical Practice Guidelines. Ann Oncol. 2012 Oct; 23 Suppl 7:vii155-66.

2. Eschenhagen T, Force T, Ewer MS, de Keulenaer GW, Suter TM, Anker SD, et al. European Society of Cardiology. Cardiovascular side effects of cancer therapies: a position statement from the Heart Failure Association of the European Society of Cardiology. Eur J Heart Fail. 2011. 13(1):1-10.

3. Magnano LC, Martínez Cibrian N, Andrade González X, Bosch. Cardiac Complications of chemotherapy: role of prevention. Curr Treat Options Cardiovasc Med. 2014 Jun; 16(6):312.

4. Hensley ML, Hagerty KL, Kewalramani T, Green DM, Meropol NJ, Wasserman TH, et al. American Society of Clinical Oncology. American Society of Clinical Oncology2008 Clinical Practice Guideline Update: Use of Chemotherapy and Radiation Therapy Protectants. J Clin Oncol. 2009. Jan 1; 27(1):127-45.

5. Todaro MC, Oreto L, Qamar R, Paterick TE, Carerj S, Khandheria BK Cardioncology: State of the heart. Int J Cardiol. 2013 Sep 30; 168(2):680-7.

6. Galderisi M, Marra F, Esposito R, Lomoriello VS, Pardo M, Divitiis 0. Cancer therapy and cardiotoxicity: the need of serial Doppler echocardiography. Cardiovasc Ultrasound. 2007 Jan 25; 5:4.

7. Dong Q, Chen L, Lu Q, Sharma S, Li L, Morimoto S, Wang G. Quercetin attenuates doxorubicin cardiotoxicity by modulating Bmi-1 expression. Br J Pharmacol. 2014 Oct; 171(19):4440-54.

8. Kobashigawa LC, Xu YC, Padbury JF, Tseng Y, Yano N. Metformin protects cardiomyocyte from doxorubicin induced cardiotoxicity through an AMP-activated protein kinase dependent signalling pathway: an in vitro study. PLos One. 2014. 9(8): e104888.

9. Argun M, Üzüm K, Sönmez MF, Özyurt A, Karabulut D, Soyersarıca Z, et al. Cardioprotective effect of metformin against doxorubicin cardiotoxicity in rats. Anatol J Cardiol. 2015 Apr 30. 